Proc. of the 15th Int. Workshop on Slow Positron Beam Techniques and Applications, Prague, September 2-6, 2019

\title{
Quenched-in Vacancies and Hardening of Fe-Al Intermetallics
}

\author{
I. Prochazka ${ }^{a, *}$, T. Vlasak ${ }^{a}$, J. CizeK ${ }^{a}$, F. LukaC ${ }^{a, b}$, M.O. Liedre ${ }^{c}$, \\ W. ANWAND ${ }^{c}$, Y. JiRASKOVA ${ }^{d}$ AND D. JANICKOVIC ${ }^{e}$ \\ ${ }^{a}$ Faculty of Mathematics and Physics, Charles University, V Holesovickach 2, 18000 Praha 8, Czech Republic \\ ${ }^{b}$ Institute of Plasma Physics of the Czech Academy of Sciences, Za Slovankou 3, 18200 Praha 8, Czech Republic \\ ${ }^{c}$ Institute of Radiation Physics, Helmholtz Zentrum Dresden-Rossendorf, \\ Bautzner Landstr. 400, 01328 Dresden, Germany \\ ${ }^{d}$ Institute of Physics of Materials, Academy of Science of the Czech Republic, \\ Žižkova 513/22, Brno 61662, Czech Republic \\ ${ }^{e}$ Institute of Physics, Slovak Academy of Science, Dubravska cesta 9, Bratislava 84511, Slovak Republic \\ The role of vacancies in hardening of $\mathrm{Fe}-\mathrm{Al}$ intermetallic alloys were studied in the present work for a wide range \\ of $\mathrm{Al}$ concentrations from 20 to 50 at\%. The alloys quenched from $1000^{\circ} \mathrm{C}$ as well as those annealed subsequently \\ at $520^{\circ} \mathrm{C}$ for $1 \mathrm{~h}$ were subject to study. Slow-positron beam experiments combined with Vicker's microhardness \\ tests were utilised. Hardness of $\mathrm{Fe}-\mathrm{Al}$ alloys exhibited a somewhat complex dependence on $\mathrm{Al}$ content which could \\ not be fully explained purely by consideration of intermetallic phases formed. This happens due to additional \\ hardening effect caused by quenched-in vacancies. The concentrations of vacancies were estimated from positron \\ back-diffusion data and found to rise for $\mathrm{Al}$ content above 25 at\%. Correlation of vacancy concentrations with \\ hardness data for the quenched and annealed alloys has revealed that hardening of alloys with a low $\mathrm{Al}$ content \\ $(<30 \mathrm{at} \%)$ is originated predominantly by anti-phase boundaries while hardening induced by quenched-in vacancies \\ dominates for alloys with a higher Al content (30-50 at\%).
}

DOI: 10.12693/APhysPolA.137.255

PACS/topics: positron annihilation spectroscopy, intermetallics, vacancies

\section{Introduction}

Iron-aluminum intermetallic alloys belong to attractive materials for industrial use. Particularly, they exhibit a low density, a high strength, and a good corrosion resistance. A low production cost of $\mathrm{Fe}-\mathrm{Al}$ alloys is also advantageous.

Physical and functional properties of $\mathrm{Fe}-\mathrm{Al}$ intermetallics are influenced by point defects and atomic ordering during slow cooling from high temperatures to room temperature (RT). The ordering appears to depend on $\mathrm{Al}$ content [1]. At $\sim 1000^{\circ} \mathrm{C}$, the $\mathrm{Fe}-\mathrm{Al}$ alloys exist in the disordered $\mathrm{A} 2$ phase. The $\mathrm{Fe}-\mathrm{Al}$ alloys with a high $\mathrm{Al}$ concentration of 30-50 at\% undergo transformation from the A2 phase to the partially ordered B2 structure when cooled down to RT. The $\mathrm{Fe}-\mathrm{Al}$ alloys with a lower $\mathrm{Al}$ content (20-30 at\%) pass first also through the A2 $\rightarrow$ B2 transition during cooling, but ordering continues with decreasing temperature reaching eventually the ordered D03 phase at RT. At high temperatures, the equilibrium concentrations of vacancies in $\mathrm{Fe}-\mathrm{Al}$ alloys become as high as several at\% [2]. Vacancies were for example shown to have a significant influence on hardness of these systems [3]. Thus comprehensive research on vacancies

*corresponding author; e-mail: ivan.prochazka@mff.cuni.cz in $\mathrm{Fe}-\mathrm{Al}$ alloys in a wide range of $\mathrm{Al}$ content is essential for complete understanding of physical and mechanical properties of these alloys.

The positron annihilation spectroscopy (PAS) has already been applied to defect studies of $\mathrm{Fe}-\mathrm{Al}$ alloys several times [4-9]. The present work was aimed to expand knowledge of $\mathrm{Fe}-\mathrm{Al}$ intermetallics and to gain more insight into the hardening role of quenched-in vacancies in $\mathrm{Fe}-\mathrm{Al}$ alloys and effects of annealing, covering a wide range of $\mathrm{Al}$ concentrations (from $\approx 20$ at $\%$ to $\approx 50 \mathrm{at} \%$ ). The variable energy positron annihilation spectroscopy (VEPAS) was combined with Vickers microhardness (HV) measurements.

\section{Experimental}

\subsection{Materials}

A series of $\mathrm{Fe}-\mathrm{Al}$ alloys, $\mathrm{Fe}_{100-c_{\mathrm{Al}}} \mathrm{Al}_{c_{\mathrm{Al}}}$, with $\mathrm{Al}$ concentrations, $c_{\mathrm{Al}}$ covering the range from 18 to 49 at $\%$ were prepared by arc melting of high-purity (99.99\%) iron and aluminium in Ti-gettered argon atmosphere. Disk-shaped $\mathrm{Fe}-\mathrm{Al}$ specimens $(\approx 15 \mathrm{~mm}$ diameter, $\approx 0.5 \mathrm{~mm}$ thickness) were cut from the cast ingot, annealed at $1000^{\circ} \mathrm{C}$ for $1 \mathrm{~h}$ in evacuated quartz ampoules and promptly quenched into water at RT. The asquenched specimens were first characterised by VEPAS or HV. Selected quenched specimens then underwent vacuum annealing at $520^{\circ} \mathrm{C}$ for $1 \mathrm{~h}$ finished by quenching into RT water and followed by the measurements. 


\subsection{Apparatus and data taking}

VEPAS investigations were carried out using a ${ }^{22} \mathrm{Na}$ based continuous magnetically guided slow positron beam [10]. Positron energies $E_{+}$, covered the interval from 0.03 to $35 \mathrm{keV}$. The $\gamma$-spectra were measured with a HPGe spectrometer exhibiting an energy resolution of $1.06 \mathrm{keV}$ (FWHM) at $511 \mathrm{keV}$. At least $2.5 \times 10^{5}$ counts were accumulated in each annihilation peak. The Doppler-broadened peak shapes were characterised through ordinary sharpness $(S)$ and wing $(W)$ parameters and normalised to values $S_{0}=0.5085 \pm 0.0010$ and $W_{0}=0.1004 \pm 0.0004$, to which measured $S$ - and $W$-values were found to level for the quenched $\mathrm{Fe}_{75} \mathrm{Al}_{25}$ reference alloy above $E_{+} \approx 20 \mathrm{keV}$. The dependences $S$ vs. $E_{+}$were analysed by means of the VEPFIT code [11].

Vickers microhardness tests were carried out by applying $100 \mathrm{~g}$ load for $10 \mathrm{~s}$ using the STRUERS Duramin-2 micro-tester. Resulting HV-values were obtained by averaging at least 10 repeated tests.

\section{Results And Discussion}

\subsection{VEPAS data}

The dependences of $S$-parameters on positron energy $E_{+}$measured for $\mathrm{Fe}-\mathrm{Al}$ alloys in the present work, exhibited patterns illustrated in Fig. 1. For $E_{+}<2 \mathrm{keV}$, a pronounced fall of the $S$-values with increasing $E_{+}$ was seen, which should be attributed to an oxide layer, that $\mathrm{Fe}-\mathrm{Al}$ alloys are known to be covered with [8]. Above $E_{+} \approx 2 \mathrm{keV}$, gradual approach of $S$-parameters toward $c_{A l}$-specific bulk values, $S_{\text {bulk }}\left(c_{A l}\right)$, was clearly visible, reflecting decreasing portion of positrons that could diffuse back to the surface, when $E_{+}$was increased.

The measured $S\left(E_{+}\right)$dependences were analysed by means of VEPFIT code [11]. In accordance with the observed shapes of these dependences, the fitting model included the two depth regions: (i) the thin (a few tens of $\mathrm{nm}$ ) surface oxide layer, and (ii) the $\mathrm{Fe}-\mathrm{Al}$ bulk. Below, we will focus on the bulk region characterised by shape parameters $S_{\text {bulk }}$ and $W_{\text {bulk }}$, and the mean positron diffusion length $L_{+, \text {bulk }}$. VEPFIT analysis of measured $W\left(E_{+}\right)$-dependences appeared to be less meaningful. $W_{\text {bulk }}$ parameters could, however, be estimated by averaging measured $W$-values over the plateau region $\left(E_{+} \geq 20 \mathrm{keV}\right)$. The bulk shape parameters were arranged in the $S_{\text {bulk }}-W_{\text {bulk }}$ plot in Fig. 2. Roughly linear behaviour is featured by this plot for the quenched as well as annealed $\mathrm{Fe}-\mathrm{Al}$ alloys, suggesting that the same defect species were dominating positron traps in the bulk region for all the $\mathrm{Fe}-\mathrm{Al}$ alloys with $\mathrm{Al}$ content between 26 and 50 at\%. For the quenched $\mathrm{Fe}-\mathrm{Al}$ alloys, the evolution of $S_{\mathrm{bulk}}{ }^{-}$and $W_{\text {bulk-values with } c_{\mathrm{Al}} \text { show a non-monotonicity around }}$ $c_{\mathrm{Al}}=26$ at $\%$, reaching the minimum in $S_{\text {bulk }}$ (maximum in $\left.W_{\text {bulk }}\right)$ at $c_{\mathrm{Al}}=26$ at $\%$. Then, $S_{\text {bulk-values }}$

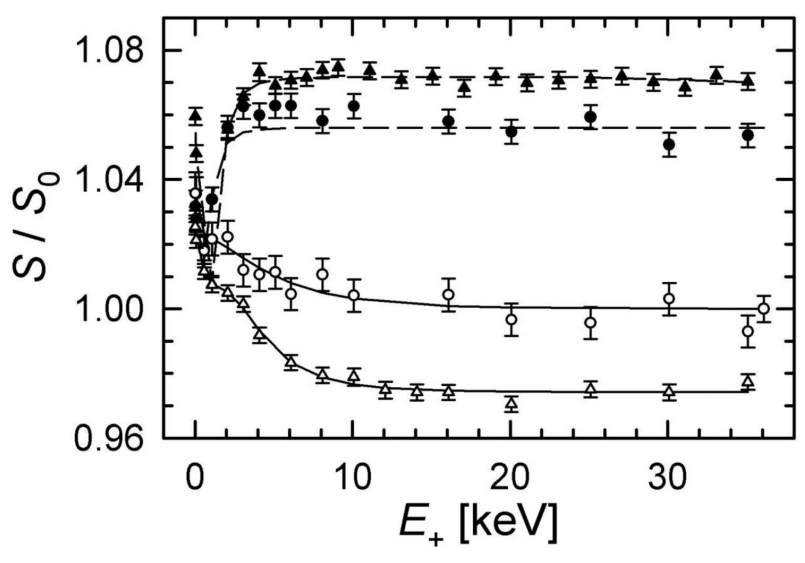

Fig. 1. Examples of measured $S$ parameters, normalised as described in the text and plotted versus positron energy $E_{+}$: $\circ-\mathrm{Fe}_{75} \mathrm{Al}_{25}, \triangle-\mathrm{Fe}_{74} \mathrm{Al}_{26}$, • - $\mathrm{Fe}_{55} \mathrm{Al}_{45}, \boldsymbol{\Delta}-\mathrm{Fe}_{51} \mathrm{Al}_{49}$. Solid and dashed lines represent the VEPFIT modelled curves.

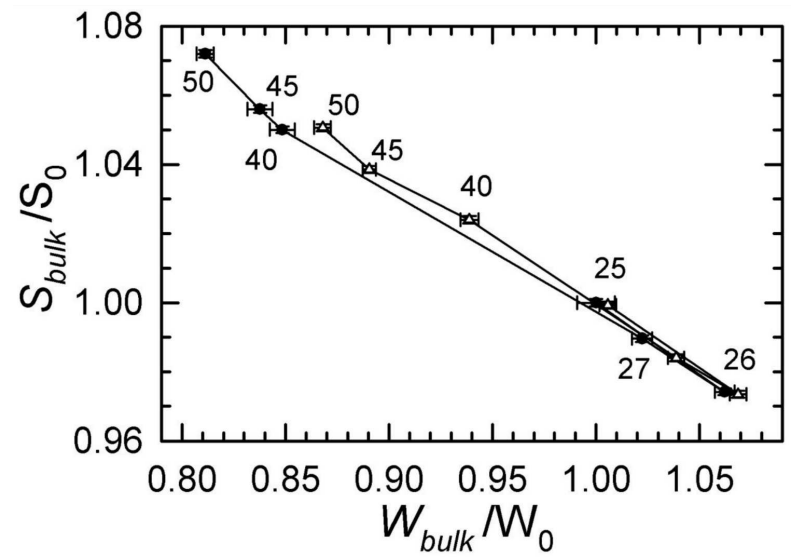

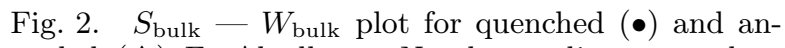
nealed $(\triangle) \mathrm{Fe}-\mathrm{Al}$ alloys. Numbers adjacent to data points denote $\mathrm{Al}$ concentration in at\%. Lines were drawn just to guide eyes.

were found to grow ( $W_{\text {bulk }}$ to decline) monotonically, see Fig. 2. For the annealed $\mathrm{Fe}-\mathrm{Al}$ alloys, the evolution of the plot remains similar to the quenched alloys, how-

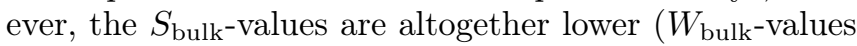
higher) than corresponding data for the quenched alloys. The decrease in $S_{\text {bulk-values for annealed alloys with re- }}$ spect to the quenched ones becomes more pronounced for $c_{\mathrm{Al}}>40 \mathrm{at} \%$. The negative slope of the $S_{\mathrm{bulk}}-W_{\mathrm{bulk}}$ line for the annealed alloys seems to be slightly higher than that for the quenched ones. In Fig. $3, L_{+}$,bulk-values obtained using VEPFIT analysis were plotted against the $\mathrm{Al}$ content. A decrease in diffusion lengths with increasing $c_{\mathrm{Al}}$ can be clearly seen in the figure, being more pronounced for the quenched alloys at higher $\mathrm{Al}$ content. The trends in $S_{\text {bulk }^{-}}, W_{\text {bulk }^{-}}$and $L_{+, \text {bulk-values }}$ displayed in Figs. 2 and 3 should be understood as a manifest of increasing role of defects in the bulk region of 


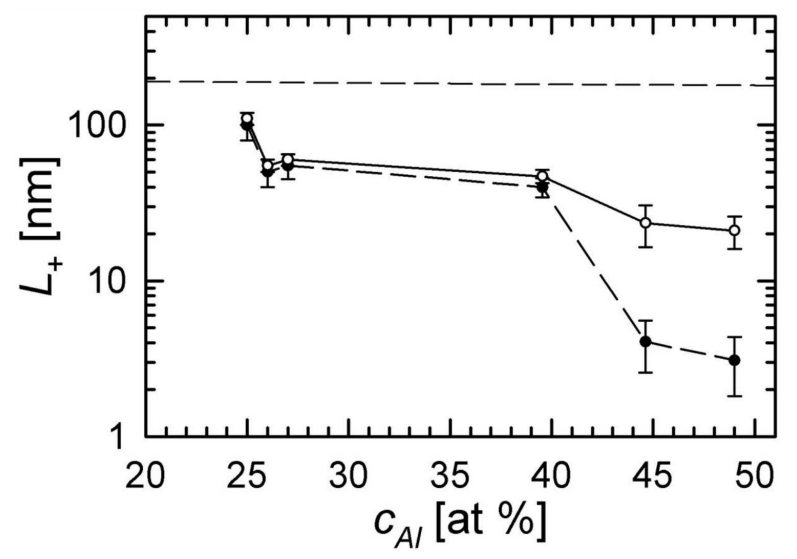

Fig. 3. Mean positron diffusion length, $L_{+, \text {bulk, }}$ in the $\mathrm{Fe}-\mathrm{Al}$ bulk plotted against $\mathrm{Al}$ content, $c_{\mathrm{Al}}$ for quenched alloys $(\bullet)$ and annealed alloys $(\boldsymbol{\Lambda}) \cdot L_{+, B}$ (dashed line) stands for positron diffusion length in perfect lattice as estimated in [8]. Lines connecting the data points were drawn just to guide eyes.

the $\mathrm{Fe}-\mathrm{Al}$ alloys when $\mathrm{Al}$ concentration was rising up from $c_{\mathrm{Al}} \approx 26$ toward 50 at $\%$. A similar conclusion could be also supported by our previous positron lifetime (LT) study of quenched $\mathrm{Fe}-\mathrm{Al}$ alloys $[8,9]$ where the dominating positron traps were identified as the quenched-in $\mathrm{Fe}$ vacancies in the $\mathrm{A}$-sublattice surrounded by $\mathrm{Al}$ neighbour atoms in the B-sublattice of which the number is growing with increasing $\mathrm{Al}$ content. A decrease of $S_{\text {bulk-values }}$ after annealing the $\mathrm{Fe}-\mathrm{Al}$ alloys is obviously a result of the recovery of the quenched-in vacancies.

The saturated positron trapping was observed by the LT technique in quenched $\mathrm{Fe}-\mathrm{Al}$ alloys with $c_{\mathrm{Al}}>26$ at\% [8] and the LT method thus became ineffective to study changes in vacancy concentrations $c_{\mathrm{V}}$ in the alloys with higher $\mathrm{Al}$ content. Note that the saturated trapping limit could be estimated as $c_{V, \text { lim }} \approx$ $2 \times 10^{-4}$ at $^{-1}$ [9]. The measurement of positron diffusion length, on the other hand, enables to estimate defect concentration in case of high defect densities in $\mathrm{Fe}-\mathrm{Al}$ alloys as demonstrated in our previous studies [8, 9]. Assuming the Fe vacancy-like defects to be dominating positron traps, the procedure relies upon relation [11]

$$
c_{\mathrm{V}}=\frac{1}{\nu_{\mathrm{V}} \tau_{B}}\left(\frac{L_{+, B}^{2}}{L_{+, \text {bulk }}^{2}}-1\right),
$$

where $\nu_{\mathrm{V}} \approx 4 \times 10^{14} \mathrm{~s}^{-1}$ is the specific positron trapping rate for a Fe-vacancy [4], $\tau_{B}$ and $L_{+, B}$, respectively, stand for the free positron lifetime $[6,12]$ and the mean positron diffusion length [9] in a perfect $\mathrm{Fe}-\mathrm{Al}$ lattice. Inserting $L_{+_{\text {bulk }}}$-values of Fig. 3 into (1) one can calculate vacancy concentrations values. They were plotted against $\mathrm{Al}$ content in Fig. 4. Figure 4 includes also the $c_{\mathrm{V}}$ value for $c_{\mathrm{Al}}=25$ deduced from the earlier LT data [8] for $\mathrm{Fe}_{75} \mathrm{Al}_{25}$, which turned out to closely coincide with the present VEPAS results. A substantial increase in the concentration of quenched-in vacancies

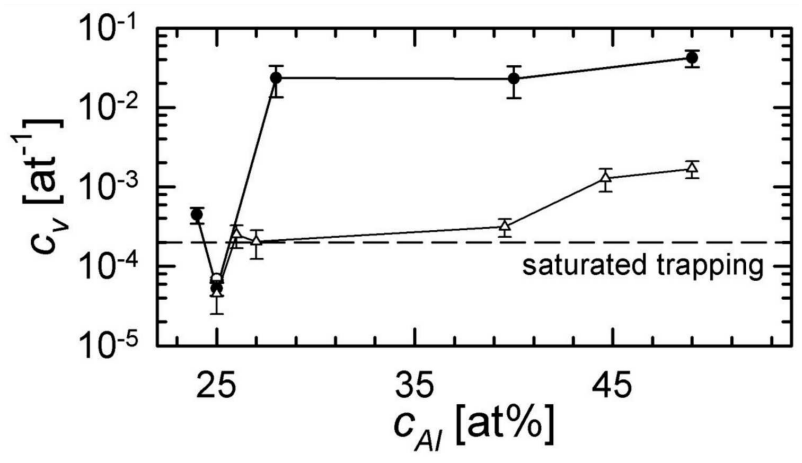

Fig. 4. Concentration of vacancies, $c_{\mathrm{V}}$, displayed as function of $\mathrm{Al}$ content, $c_{\mathrm{Al}}$ : $\bullet-$ quenched alloys, $\triangle$ - annealed alloys, o- LT result [8]. Vacancy concentrations were estimated from VEPAS experiments according to (1). Solid lines were drawn just to guide eyes. Dashed line stands for saturated trapping limit [8].

with increased $\mathrm{Al}$ content was observed. In addition, a drop in the vacancy concentration in the annealed samples, compared to the quenched ones, is seen in Fig. 4, progressing markedly with increasing $\mathrm{Al}$ content above $c_{\mathrm{Al}} \approx 26 \mathrm{at} \%$.

\section{2. $H V$ data}

Microhardness values measured for quenched and annealed $\mathrm{Fe}-\mathrm{Al}$ alloys were collected in Fig. 5 as functions of $\mathrm{Al}$ concentration $c_{\mathrm{Al}}$. Similarly to the VEPAS results, the data showed a non-monotonic behaviour: For quenched alloys, the $\mathrm{HV}$-values first grew from $c_{\mathrm{Al}} \approx 20$ at $\%$ reaching a broad maximum at $c_{\mathrm{Al}} \approx 27 \mathrm{at} \%$. Then they exhibited a visible drop between $c_{\mathrm{Al}} \approx 27$ and $\approx 30$ at $\%$. Above $c_{\mathrm{Al}} \approx 30 \mathrm{at} \%$, another rise up of $\mathrm{HV}$ toward alloys with higher $\mathrm{Al}$ content was seen. After annealing at $520^{\circ} \mathrm{C}$ per $1 \mathrm{~h}$, only minor differences in hardness between quenched and annealed $\mathrm{Fe}-\mathrm{Al}$ samples were found below $c_{\mathrm{Al}}=27 \mathrm{at} \%$. Whereas, a remarkable decline of $\mathrm{HV}$ with respect to the quenched samples for $\mathrm{Al}$ content above $\approx 27$ at $\%$ took place and this difference became gradually enlarged with increasing $\mathrm{Al}$ concentration, obviously reflecting an increasing vacancy concentration $c_{\mathrm{V}}$ revealed in this $c_{\mathrm{Al}}$ region by the VEPAS data of Sect. 3.1 as well as by earlier LT results [8]. Undoubtedly, such decrease should be due to annihilation of quenched-in vacancies during annealing. In annealed alloys, the $\mathrm{HV}$-values were kept roughly stable between $C_{\mathrm{Al}} \approx 30$ and $\approx 40$ at $\%$ indicating that applying of annealing at $520^{\circ} \mathrm{C}$ for $1 \mathrm{~h}$ had been sufficient to anneal out a majority of quenched-in vacancies. Then a slight increase in $\mathrm{HV}$ was observed, see Fig. 5, resulting probably from contribution of triple defects (two aligned Fe vacancies in the A sublattice associated with an antisite Fe atom in the B sublattice). In fact, an increasing role of triple defects, which in Al-rich alloys is around $c_{\mathrm{Al}} \approx 50$ at\%, was evidenced in our earlier positron lifetime measurements [8]. 


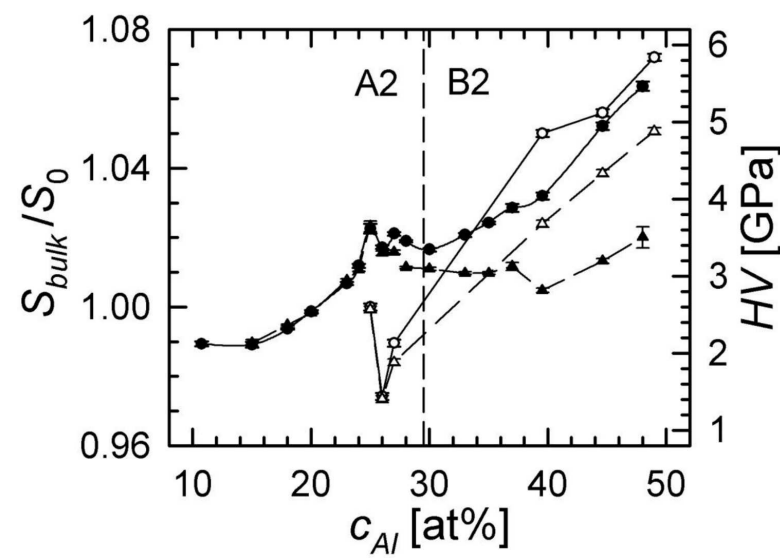

Fig. 5. Normalised $S_{\text {bulk }}$ parameter and microhardness $\mathrm{HV}$ plotted against $\mathrm{Al}$ content, $c_{\mathrm{Al}}$ : Empty symbols $S_{\text {bulk }}$, filled symbols - HV; circles - quenched alloys, triangles - annealed alloys $\left(520^{\circ} \mathrm{C}\right.$ per $\left.1 \mathrm{~h}\right)$. Lines were drawn just to guide eyes.

In Fig. 5, we have also plotted the normalised

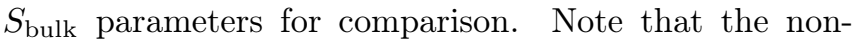
monotonicity exhibited in the figure by HV closely coincides with that of $S_{\text {bulk }}$, pointing out to a common cause of both effects - intermetallic phases formed depending on $\mathrm{Al}$ content. The behaviour of $\mathrm{HV}$ in the whole range of $c_{\mathrm{Al}}$ (called as the total hardness $\mathrm{HV}_{\text {tot }}$ ) should thus be described by the two mechanisms in the following way

$$
\mathrm{HV}_{\text {tot }}=\mathrm{HV}_{c}\left(c_{\mathrm{Al}}\right)+\mathrm{HV}_{\mathrm{V}}\left(c_{\mathrm{V}}\right) \text {. }
$$

The first term in above equation, $\mathrm{HV}_{c}\left(c_{\mathrm{Al}}\right)$, expresses hardening controlled by $\mathrm{Al}$ content. In turn the second term, $\mathrm{HV}_{\mathrm{V}}\left(c_{\mathrm{V}}\right)$, is about the additional hardening induced by quenched-in vacancies. Due to low vacancy concentration, the vacancy-induced hardening is too small in alloys with $c_{\mathrm{Al}}<27$ at\%, leaving likely the antiphase boundaries to be the main contribution to hardness in this region of $\mathrm{Al}$ concentrations. For $c_{\mathrm{Al}}$ above 30 at\%, both hardening mechanisms become important. It seems plausible to assume that after annealing at $520^{\circ} \mathrm{C}$ for $1 \mathrm{~h}$ an overwhelming majority of vacancies were already annealed out and, hardening controlled by $\mathrm{Al}$ content is not significantly influenced by annealing, i.e., the hardness values measured for the annealed alloys approximate sufficiently the $\mathrm{HV}_{c}\left(c_{\mathrm{Al}}\right)$ term in (2). Under such assumptions, the $\mathrm{HV}_{\mathrm{V}}\left(c_{\mathrm{V}}\right)$ can be extracted as the difference between the total hardness for quenched and annealed alloys, namely

$$
\mathrm{HV}_{\mathrm{V}}\left(c_{\mathrm{V}}\right) \approx \mathrm{HV}_{\mathrm{tot}}^{(q)}-\mathrm{HV}_{\mathrm{tot}}^{(a)},
$$

where superscripts $q$ and $a$ distinguish quenched and annealed alloys, respectively.

Quenched-in vacancies are obstacles pining dislocations. In this case, $\mathrm{HV}_{\mathrm{V}}\left(c_{\mathrm{V}}\right)$ can be written [13] as

$$
\mathrm{HV}_{\mathrm{V}}\left(c_{\mathrm{V}}\right)=\mathrm{HV}_{\mathrm{V}}^{(0)}+6 \mu \gamma \sqrt{c_{\mathrm{V}}} \text {, }
$$

where $\mu \approx 100 \mathrm{GPa}$ is the shear modulus of $\mathrm{Fe}-\mathrm{Al}$ [14], $\gamma<1$ stands for the strength of vacancy-dislocation interaction and $\mathrm{HV}_{\mathrm{V}}^{(0)}$ is the hardness at zero $c_{V}$.

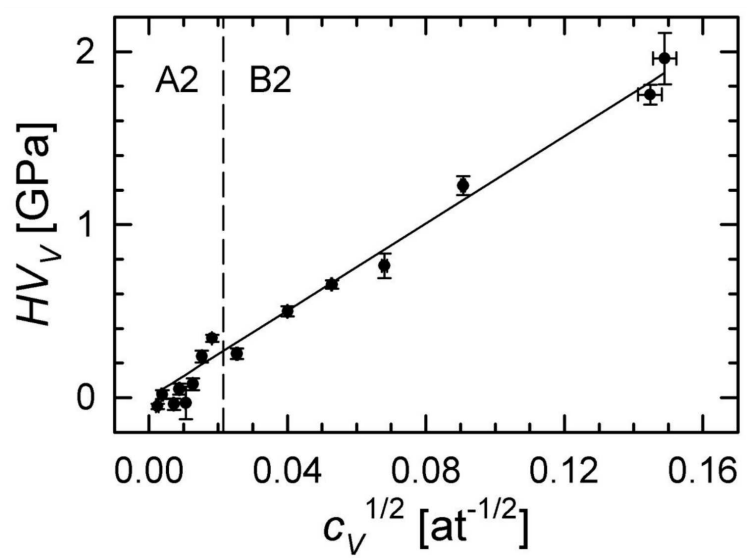

Fig. 6. Correlation between microhardness and vacancy concentration. See the text for further explanations.

The hardness data expressed in Fig. 5 as function of $\mathrm{Al}$ content could be converted into to the dependence on vacancy concentration $c_{\mathrm{V}}$. This can be done using the VEPAS results of Fig. 4 as calibration points for the $c_{\mathrm{V}}$-scale. Correlation of the $\mathrm{HV}_{\mathrm{V}}\left(c_{\mathrm{V}}\right)$ evaluated from the measured total hardness values using (3), is displayed on Fig. 6 against $\sqrt{c_{V}}$. The solid line in the figure represents the $\mathrm{HV}_{\mathrm{V}}\left(c_{\mathrm{V}}\right)$-values calculated inserting $\mathrm{HV}_{\mathrm{V}}^{(0)} \approx 0$ and $\gamma \approx 0.2$ into (4). Indeed, approaching the $\mathrm{HV}_{\mathrm{V}}^{(0)}$ to zero may be expected. The $\gamma$-value, i.e., the slope of the line is about twice lower, yet of the same order, as that obtained for similar $\mathrm{Fe}-\mathrm{Al}$ alloys in [13], supporting thus the above considerations.

\section{Conclusions}

The results of the present work can be summarised as follows:

1. The concentrations of vacancies in a series of $\mathrm{Fe}-\mathrm{Al}$ alloys with different $\mathrm{Al}$ contents (18 to $49 \mathrm{at} \% \mathrm{Al}$ ), quenched from $1000{ }^{\circ} \mathrm{C}$ to room temperature, were estimated from positron back-diffusion study using the slow-positron beam technique. The concentration of quenched-in vacancies was found to strongly grow with increasing $\mathrm{Al}$ content.

2. Microhardness data and bulk $S$ parameters, obtained for $\mathrm{Fe}-\mathrm{Al}$ alloys with different $\mathrm{Al}$ content, exhibited non-monotonic behaviour in dependence on $\mathrm{Al}$ content around $c_{\mathrm{Al}} \approx 26$ at $\%$.

3. Vacancy concentration data were correlated with microhardness measurements, which allowed to conclude that (a) hardening of $\mathrm{Fe}-\mathrm{Al}$ alloys with low $\mathrm{Al}$ content $(<27$ at\%) is likely caused mainly by anti-phase boundaries and, (b) an additional mechanism, viz., vacancy-induced hardening, contributes to hardening in the $\mathrm{Fe}-\mathrm{Al}$ alloys with higher $\mathrm{Al}$ content (>30 at\%). 


\section{Acknowledgments}

Support by the Charles University Grant Agency (project 1506119) is highly acknowledged.

\section{References}

[1] Binary Alloy Phase Diagrams, (2nd Ed.), Eds. T.B. Massalski, H. Okamoto, P.R. Subramanian, L. Kacprzak, ASM International, Materials Park (OH) 1990.

[2] K. Ho, R.A. Dodd, Scr. Metall. 12, 1055 (1978).

[3] T. Liu, E.H. Lee, C.G. McKamey, Scr. Metall. 23, 875 (1989).

[4] H.E. Schaefer, B. Damson, M. Weller, E. Arzt, E.P. George, Phys. Status Solidi (a) 160, 531 (1997).

[5] J. del Rio, N. de Diego, J.A. Jiménez, C. Gómez, Intermetallics 18, 1306 (2010).

[6] O. Melikhova, J. Cizek, J. Kuriplach, I. Prochazka, M. Cieslar, W. Anwand, G. Brauer, Intermetallics 18, $592(2010)$.
[7] J. Cizek, F. Lukac, O. Melikhova, I. Prochazka, R. Kuzel, Acta Mater. 59, 4068 (2011).

[8] J. Cizek, F. Lukac, I. Prochazka, R. Kuzel, Y. Jiraskova, D. Janickovic, W. Anwand, G. Brauer, Physica B 407, 2659 (2012).

[9] F. Lukac, J. Cizek, I. Prochazka, Y. Jiraskova, D. Janickovic, W. Anwand, G. Brauer, J. Phys.: Conf. Ser. 443, 012025 (2013).

[10] W. Anwand, G. Brauer, M. Butterling, H.R. Kissener, A. Wagner, Defect Diffus. Forum 331, 25 (2012).

[11] A. van Veen, H. Schut, J. de Vries, R.A. Hakvoort, M.R. Ijpma, AIP Conf. Proc. 218, 171 (1990).

[12] J. Kuriplach, Phys. Procedia 35, 69 (2012).

[13] Y.A. Chang, L.M. Pike, C.T. Liu, A.R. Bilbrey, D.S. Stone, Intermetallics 1, 107 (1993).

[14] A. Wolfenden, M. Harmouche, J. Metals 35, 90 (1983). 